\title{
Botulinum Toxin Type A Injections as Monotherapy for Upper Limb Essential Tremor Using Kinematics
}

\author{
Olivia Samotus, Niraj Kumar, Philippe Rizek, Mandar Jog
}

\begin{abstract}
Background: There is a significant need for a targeted therapy for essential tremor (ET), as medications have not been developed specifically for ET, and the ones prescribed are often not well-tolerated, so that many patients remain untreated. Recent work has shown that, unlike previous experience, kinematically guided individualized botulinum toxin type A (BoNT-A) injections provide benefit along with minimal weakness. Ours is the first long-term (96-week) safety and efficacy study of BoNT-A as monotherapy for ET using kinematically driven injection parameters. Methods: Ten ET patients were administered six serial BoNT-A treatments every 16 weeks and were assessed at 6 weeks following treatment. During each study visit, the Fahn-TolosaMarin (FTM) scale, the Unified Parkinson's Disease Rating Scale, and the Quality of Life for Essential Tremor Questionnaire (QUEST) were administered along with kinematic assessment of the treated limb. Participants performed scripted tasks with motion sensors placed over each arm joint. Dosing patterns were determined using the movement disorder neurologist's interpretation of muscles contributing to the kinematically analyzed upper limb tremor biomechanics. Results: There was a 33.8\% $(p<0.05)$ functional improvement $($ FTM part C) and a 39.8\% $(p<0.0005)$ improvement in QUEST score at week 96 compared to pretreatment scores at week 0 . Although there was a $44.6 \%(p<0.0005)$ non-dose-dependent reduction in maximal grip strength, only 2 participants complained of mild weakness. Following the fourth serial treatment, mean action tremor score was reduced by $62.9 \%(p=0.001)$ in the treated and by $44.4 \%(p=0.03)$ in the untreated arm at week 96 compared to week 48. Conclusions: Individualized BoNT-A dosing patterns to each individual's tremor biomechanics provided an effective monotherapy for ET as function improved without functionally limiting muscle weakness.
\end{abstract}

RÉSUMÉ: Utilisation d'une monothérapie pour les tremblements essentiels des membres supérieurs : l'injection de toxine botulinique de type A au moyen de la cinématique. Contexte: Il existe un besoin réel pour un traitement ciblant les tremblements essentiels (TE) car les médicaments actuels n'ont pas été conçus précisément pour cette maladie neurologique. Ceux qu'on prescrit ne sont pas souvent très bien tolérés de sorte que de nombreux patients demeurent sans soins. Cela dit, une étude récente a montré, contrairement à une expérience menée antérieurement, que des injections de toxine botulinique de type $\mathrm{A}$, à la fois individualisées et guidées cinématiquement, ont pu procurer des bénéfices à des patients sans que ces derniers ne ressentent une fatigue autre que minime. Notre étude est par ailleurs la première visant à évaluer à long terme (96 semaines) et au moyen de paramètres d'injection guidés cinématiquement la sécurité et l'efficacité de la toxine botulinique de type A à titre de monothérapie pour les TE. Méthodes: À toutes les seize semaines, on a administré un traitement de toxine botulinique de type A à dix patients atteints de TE, soit six traitements au total. Ces patients ont été ensuite évalués six semaines après chaque traitement. À l'occasion de chaque visite en lien avec notre étude, nous les avons soumis à divers outils d'évaluation: l'échelle clinique de Fahn-Tolosa-Marin (FTM), la Unified Parkinson's Disease Rating Scale et un questionnaire mesurant la qualité de vie des patients atteints de TE (Quality of Life for Essential Tremor Questionnaire ou QUEST). Nous avons aussi procédé à une évaluation cinématique des membres traités. Munis d'un capteur de mouvement sur chaque articulation du bras, nos patients ont alors exécuté des tâches prédéterminées. Quant à la posologie, elle a été déterminée en tenant compte de l'avis d'un neurologue spécialiste des troubles du mouvement en regard des muscles responsables des tremblements affectant les membres supérieurs. Le tout a été ensuite analysé de façon cinématique et biomécanique. Résultats: En vertu de l'échelle de FTM (section C), on a observé une amélioration fonctionnelle de 33,8\% ( $p<0,05)$; en ce qui regarde le score au questionnaire QUEST, l'amélioration a été de 39,8\% ( $p<0,0005)$ à la $96^{\mathrm{e}}$ semaine en comparaison avec les scores de prétraitement à la semaine 0 . Bien qu'on ait pu noter, peu importe la posologie administrée, une réduction de 44,6\% $(p<0,0005)$ de la force de préhension maximale, seulement 2 patients se sont plaints de faiblesse légère aux membres supérieurs. À la suite du quatrième traitement administré, le score moyen en matière de tremblements à la suite de l'exécution d'une tâche a été réduit de $62,9 \%(p=0,001)$ dans le cas d'un membre traité et de 44,4\% $(p=0,03)$ dans le cas d'un membre non-traité, et ce, en comparant la $96^{\mathrm{e}}$ semaine à la $48^{\mathrm{e}}$. Conclusions: Une posologie individualisée de toxine botuliniques de type A adaptée à la biomécanique des tremblements affectant chaque individu a constitué une monothérapie efficace pour les TE. L'exécution de tâches par ces patients s'est ainsi améliorée sans que leur faiblesse musculaire ne s'aggrave.

Keywords: Essential tremor, Botulinum toxin type A, Kinematics, Biomechanics, Upper limb

doi:10.1017/cjn.2017.260

Can J Neurol Sci. 2018; 45: 11-22

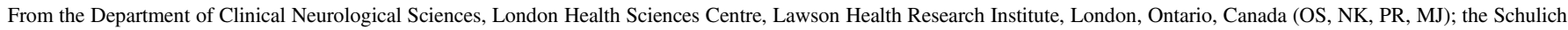
School of Medicine and Dentistry, University of Western Ontario, London, Ontario, Canada (OS, MJ).

Received November 3, 2016. Final Revisions Submitted July 11, 2017. Date of Acceptance August 15, 2017.

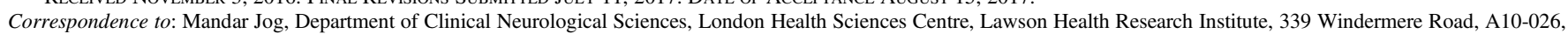

London, Ontario, Canada, N6A 5A5. Email: mandar.jog@lhsc.on.ca 


\section{INTRODUCTION}

Essential tremor (ET) is the most common adult-onset movement disorder after restless legs syndrome. ${ }^{1}$ The prevalence of ET increases with age, affecting 2.3-14.3\% of those aged 60 years and older. ${ }^{1}$ ET is diagnosed clinically based on the presence of a progressive action tremor involving the upper extremities $(\geq 95 \%)$ and less commonly the head $(\geq 34 \%)$, voice $(\geq 12 \%)$, and lower extremities $(30 \%)$, often resulting in significant physical and psychosocial disability. ${ }^{2}$ Treatment options currently available for ET include oral pharmacological agents, botulinum toxin A (BoNT-A) injection, and stereotactic surgery, including deep brain stimulation (DBS) and thalamotomy. ${ }^{3-5}$ As the basic neuropathology and neurotransmitter deficits in ET are largely unknown, no disease-specific drug is available, and all traditional oral agents used in treating ET were primarily developed for treatment of other diseases. ${ }^{3}$ Various drugs, including propranolol, the only pharmacotherapy approved through the U.S. Food and Drug Administration (FDA) to date, primidone, benzodiazepines, gabapentin, pregabalin, topiramate, and nimodipine are used in the treatment of ET, with an average tremor reduction of $50 \%$ or less. ${ }^{3,5,6}$ Poor efficacy is frequently coupled with doselimiting side effects, such as drowsiness with primidone and bradycardia, syncope, fatigue, and erectile dysfunction with propranolol, and along with tolerance to the initial benefit, often leads to discontinuation of these drugs in $56.3 \%$ of patients. ${ }^{3,5} \mathrm{DBS}$ of the ventral intermediate (VIM) nucleus of the thalamus may benefit patients with disabling ET, though only a fraction of patients are eligible for this highly invasive procedure that may produce lasting neurological side effects, including paresthesias (6-36\%), dysarthria (3-18\%), ataxia (6\%), limb weakness (4-8\%), balance disturbance (3-8\%), and dystonia (2-9\%). ${ }^{3,4}$ The efficacy and risks of gamma knife thalamotomy are comparable to VIM-DBS. ${ }^{4}$ Ultrasound-guided thalamotomy can be performed only unilaterally and again carries the same potential risks as gamma knife surgery, and thus large, randomized, controlled trials are required to assess the procedure's efficacy and safety. ${ }^{7-9}$ A review of the current recommended treatment options for ET is summarized in Table 1. Thus, the use of BoNT-A, which improves both postural and kinetic tremor, ${ }^{10-13}$ appears to be an effective therapy to fulfill the significant unmet need in the treatment of ET faced by clinicians today.

While BoNT-A injection in the upper extremities is a viable treatment option for ET, limited functional efficacy due to dosedependent wrist and finger muscle weakness remains a concern. The use of injection protocols involving fixed BoNT-A dosages and predetermined muscle sites, regardless of a patient's unique tremor characteristics, are probable reasons for this problem. ${ }^{10,11}$ During tremor assessment, the characterization of the movement dynamics along the whole arm, muscle selection, dosing, and proper localization during injection are important considerations when utilizing BoNT-A to reduce functional disability caused by tremor with a minimal likelihood of weakness. ${ }^{13-15}$ While clinical knowledge and use of such technologies as electromyography (EMG) or ultrasound aid in muscle localization and injection, visually guided assessments to characterize tremulous movements at various joints are likely to fail due to the variability and complexity of tremor and the difficulty in accurately separating multijoint whole-arm movements. Thus, the lack of adequate tremor assessment tools and poor injection guidelines have limited the use of BoNT-A for ET. ${ }^{14-16}$
The use of well-established kinematic technology for tremor characterization is a reliable and feasible methodology and can be used to accurately pinpoint tremulous muscle groups for BoNT-A therapy. ${ }^{13,15,17,18}$ Thus, kinematics provides an individualized multijoint movement pattern that can reduce the likelihood of dose-dependent weakness and thereby improve the functional efficacy of BoNT-A for ET. Recent work from our pilot studies has demonstrated the efficacy and tolerability of three serial kinematic-guided BoNT-A treatments for ET and PD tremor. ${ }^{13,15}$ Due to the lack of efficacy of the available medications for ET and their systemic adverse effects, ET patients were reluctant to take them as a first-line therapy and thus chose to receive BoNT-A injections. This article reports the first and longest open-label study on the efficacy and safety of monotherapy BoNT-A in 10 ET patients who received 6 BoNT-A injection treatments based upon kinematically guided muscle selection criteria for upper-limb ET tremor every 16 weeks over a 96-week period.

\section{METHODS}

The following methodology has been previously described. ${ }^{13,15}$ This was an open-label, single-center, single-injector pilot study reporting on 10 of the total convenience sampling of 25 ET participants recruited from the London Movement Disorders Centre in London, Ontario, Canada. The Western University Health Sciences Research Ethics Board approved this clinical phase IIb pilot study protocol, and the study and other studies involving this intervention are registered (ClinicalTrials.gov: NCT02427646). The study protocol included ET participants with suboptimally treated upper-limb tremor by oral medications or those reluctant to use oral medications as a first-line therapy and thus chose to receive BoNT-A injections. All therapeutic options were presented to the participants. From the total of 24 ET participants included in this open-label study, 10 ET participants were naïve to both BoNT-A and oral medications. These 10 participants provided written consent and were chosen for analysis, as they were naïve to all ET oral medications. The study's progress is outlined in the CONSORT flowchart depicted in Figure 1. The first visit of the first participant and the last visit of the final participant occurred in April of 2012 and May of 2015, respectively.

BoNT-A injection treatments were administered every 16 weeks starting at week 0 , with a follow-up study visit occurring 6 weeks postinjection, for a total of 13 study visits over 96 weeks. Participants who were naïve to medication maintained monotherapy with BoNT-A injections for their tremor throughout the duration of the study. Participants were assessed at approximately the same time of day for all visits. Each visit included completing clinical rating scales and kinematic assessment of upper-limb tremor. The tremor-dominant limb was treated with BoNT-A (incobotulinumtoxinA; Xeomin ${ }^{\circledR}$, Merz Pharma, Frankfurt, Germany) under EMG guidance, using a Clavis ${ }^{\circledR}$ (Natus Medical Inc., San Diego, California, USA) portable EMG device, with a 1"-long 30-gauge injectable EMG needle $(0.5 \mathrm{~mL}$ of saline per 100 -unit vial dilution to minimize liquid volume and therefore spread of BoNT-A). The kinematic device has been approved by the FDA and Health Canada for use in clinical trials and is being commercialized. The average time per arm for kinematic assessment is 15 minutes. 
Table 1: Current, recommended treatment options for ET

\begin{tabular}{|c|c|c|c|c|c|c|c|}
\hline Drug name & Drug class & $\begin{array}{l}\text { Level/ } \\
\text { class }\end{array}$ & $\begin{array}{l}\text { Total daily } \\
\text { dosage } \\
(\mathrm{mg} / \mathrm{d})\end{array}$ & $\begin{array}{l}\text { Sample } \\
\text { size }\end{array}$ & Efficacy (compared to baseline) & Adverse effects & $\begin{array}{l}\text { Review } \\
\text { reference }\end{array}$ \\
\hline Propranolol & Beta blocker & A & $40-320$ & 533 & $\begin{array}{l}\sim 50 \% \text { of patients respond. Those that } \\
\text { respond experience a } 50-60 \% \\
\text { reduction in tremor }\end{array}$ & $\begin{array}{l}\text { Nausea, vomiting, bradycardia, diarrhea, } \\
\text { hypotension, drowsiness, fatigue, } \\
\text { light-headedness, weakness, and } \\
\text { paresthesia }\end{array}$ & 29,31 \\
\hline Primidone & Anticonvulsant & A & $50-1000$ & 218 & $\begin{array}{l}50 \% \text { mean improvement rated by } \\
\text { clinical scales and accelerometry }\end{array}$ & $\begin{array}{l}\text { Ataxia, vertigo, nausea, vomiting, } \\
\text { fatigue, malaise, dizziness, } \\
\text { unsteadiness, confusion, impotence, } \\
\text { rash }\end{array}$ & $29-31$ \\
\hline Atenolol & Beta blocker & B & $50-150$ & 79 & $\begin{array}{l}25 \% \text { mean improvement by clinical } \\
\text { scales, } 37 \% \text { mean improvement by } \\
\text { accelerometry }\end{array}$ & $\begin{array}{l}\text { Light-headedness, nausea, cough, dry } \\
\text { mouth, sleepiness, decreased pulse and } \\
\text { blood pressure }\end{array}$ & 29,30 \\
\hline Alprazolam & $\begin{array}{l}\text { Benzo- } \\
\text { diazepine }\end{array}$ & B & $0.125-3$ & 46 & $\begin{array}{l}25-37 \% \text { mean improvement by } \\
\text { clinical scales }\end{array}$ & Mild sedative and fatigue effects & 29,30 \\
\hline $\begin{array}{l}\text { Gabapentin } \\
\text { (monotherapy) }\end{array}$ & Anticonvulsant & B & $1200-1800$ & 61 & $\begin{array}{l}33 \% \text { improvement by clinical scales, } \\
77 \% \text { improvement by } \\
\text { accelerometry }\end{array}$ & $\begin{array}{l}\text { Drowsiness, fatigue, dizziness, } \\
\text { nervousness, shortness of breath, } \\
\text { reduced libido }\end{array}$ & $29-31$ \\
\hline Sotalol & $\begin{array}{l}\text { Beta-adrenergic } \\
\text { receptor } \\
\text { antagonist }\end{array}$ & $\mathrm{B}$ & $75-240$ & 50 & $\begin{array}{l}28 \% \text { mean improvement in clinical } \\
\text { scales }\end{array}$ & $\begin{array}{l}\text { Serious ventricular arrhythmias, dose- } \\
\text { related QT interval prolongation, } \\
\text { reduced alertness }\end{array}$ & $7,29,30$ \\
\hline Topiramate & Anticonvulsant & $\mathrm{B}$ & $25-300$ & 335 & $\begin{array}{l}29 \% \text { improvement in clinical scales } \\
\text { (mean dose }=292 \mathrm{mg} / \mathrm{d} \text { ); } 30 \% \\
\text { improvement in tremor (up to } \\
400 \mathrm{mg} / \mathrm{d} \text { ) with a } 32 \% \text { attrition rate } \\
\text { due to adverse events }\end{array}$ & $\begin{array}{l}\text { Dizziness, disorientation, paresthesia, } \\
\text { weight loss, memory difficult, appetite } \\
\text { suppression, cognitive difficulties, } \\
\text { upper respiratory tract infection, taste } \\
\text { perversion, fatigue, nausea, headache, } \\
\text { somnolence }\end{array}$ & 30,31 \\
\hline Nimodipine & $\begin{array}{l}\text { Calcium } \\
\text { channel } \\
\text { blockers }\end{array}$ & $\mathrm{C}$ & 120 & 16 & $\begin{array}{l}45 \% \text { improvement by clinical scales } \\
\text { and } 53 \% \text { improvement by } \\
\text { accelerometry }(n=14)\end{array}$ & Headache, heartburn, hypotension & 29,30 \\
\hline Clonazepam & Benzodiazepine & $\mathrm{C}$ & $0.5-6$ & 44 & $45 \%$ improvement by accelerometry & $\begin{array}{l}\text { Drowsiness, depression, cognitive and } \\
\text { behavioral impairments }\end{array}$ & 29,30 \\
\hline BoNT-A & Neurotoxin & $\mathrm{C}$ & $\begin{array}{l}50-300 \\
\text { U/arm }\end{array}$ & 283 & $\begin{array}{l}20-27 \% \text { improvement by clinical } \\
\text { scales }(n=133)\end{array}$ & $\begin{array}{l}\text { Dose-dependent muscle weakness } \\
\text { occurred in } 30 \% \text { of patients, reduced } \\
\text { grip strength, stiffness, cramping, pain } \\
\text { at injection site }\end{array}$ & $29,30,35$ \\
\hline $\begin{array}{l}\text { Deep brain } \\
\text { stimulation }\end{array}$ & $\begin{array}{l}\text { Unilateral or } \\
\text { bilateral } \\
\text { VIM-DBS; } \\
\text { STN-DBS }\end{array}$ & $\mathrm{C}$ & & 398 & $\begin{array}{l}\text { 40-90\% improvement by clinical } \\
\text { scales up to } 3 \text { years; chronic } \\
\text { stimulation gradually worsens } \\
\text { efficacy, leading to loss of tremor } \\
\text { suppression in about } 70 \% \text { of } \\
\text { patients }\end{array}$ & $\begin{array}{l}\text { Dysarthria, disequilibrium, paresthesias, } \\
\text { weakness, headache, intracranial } \\
\text { hemorrhage, subdural hemorrhage, } \\
\text { lead dislodgement, generalized motor } \\
\text { seizures; about } 18 \% \text { experience } \\
\text { equipment malfunction or lead } \\
\text { displacement }\end{array}$ & 29,35 \\
\hline Thalamotomy & $\begin{array}{l}\text { Gamma knife; } \\
\text { MRI-guided } \\
\text { focused } \\
\text { ultrasound }\end{array}$ & $\mathrm{C}$ & & 181 & $\begin{array}{l}55-90 \% \text { improvement by clinical } \\
\text { scales }\end{array}$ & $\begin{array}{l}\text { Hemiparesis, transient problems with } \\
\text { speech, motor function, dysarthia, } \\
\text { verbal/cognitive deficit, weakness, } \\
\text { confusion, facial paresis; about } 7 \% \\
\text { experience permanent complications } \\
\text { (hemorrhage and infection). }\end{array}$ & $8,29,30$ \\
\hline
\end{tabular}

Levels of evidence are derived from the American Academy of Neurology recommendations: $\mathrm{A}=$ established effective, $\mathrm{B}=$ probably effective, $\mathrm{C}=$ possibly effective, $\mathrm{U}=$ data inadequate or conflicting.

\section{Study Eligibility Criteria}

Participants included in the study were consenting males and females diagnosed with ET as their primary and functionally impairing symptom, aged 18 to 80 years, and naïve to BoNT-A and any oral antitremor medications. Participant criteria excluded those who had a history of stroke, had contraindications per the incobotulinumtoxinA drug monograph, ${ }^{19}$ were pregnant, and had been prescribed zonisamide and existing pharmacological therapy with tremor-inducing side effects.

\section{Clinical Scale Assessment}

Severity of tremor, overall quality of life $(\mathrm{QoL})$, and functional disability caused by tremor were measured using well-established rating scales. QoL was scored using the Quality of Life for Essential Tremor Questionnaire (QUEST), ${ }^{20}$ and tremor severity and functional ability were assessed by the Fahn-Tolosa-Marin (FTM) scale for each participant per study visit. ${ }^{21}$ The Unified Parkinson's Disease Rating Scale (UPDRS) part III (motor examination), items 20 and $21,{ }^{22}$ rest and action tremor, 


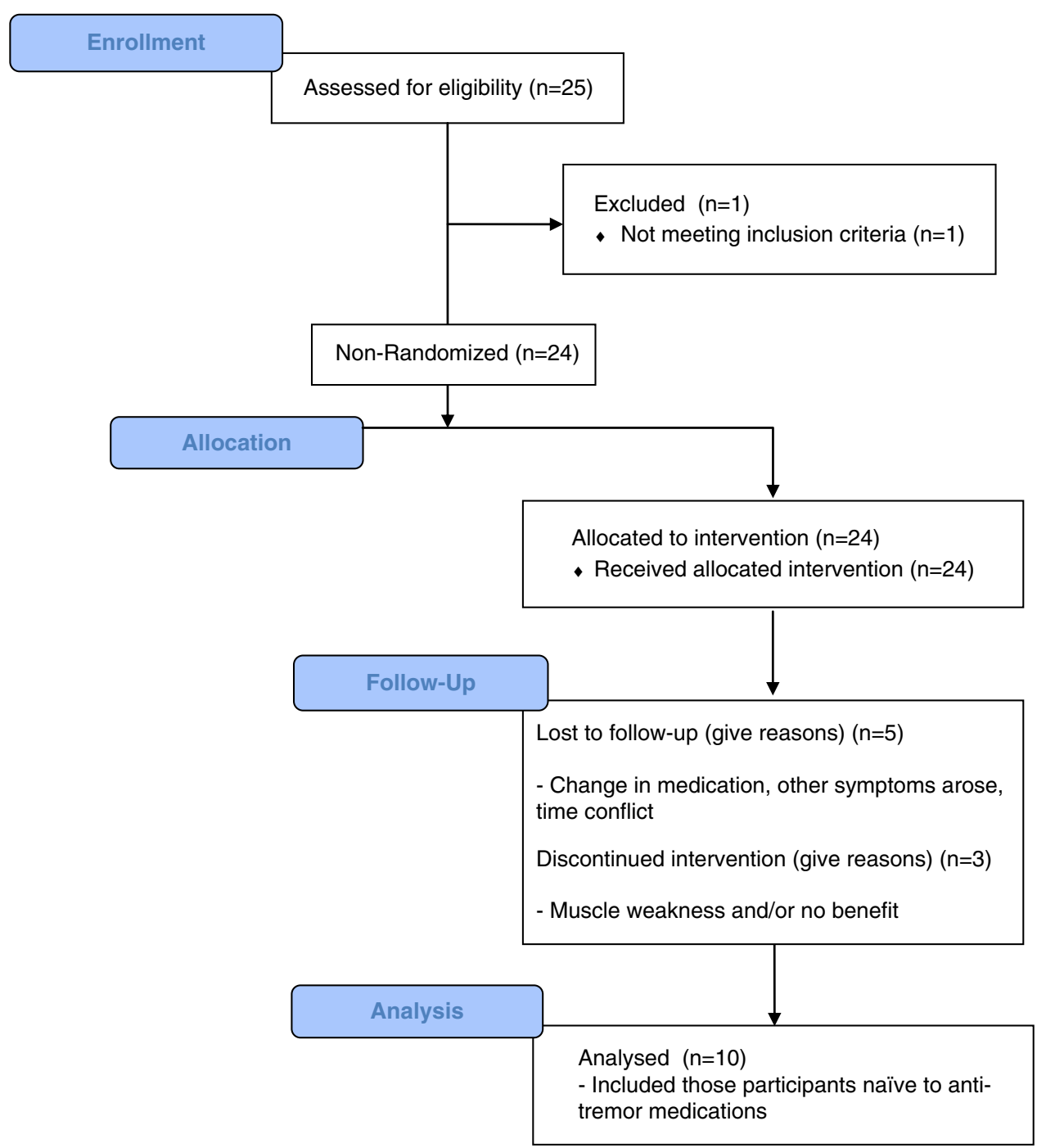

Figure 1: CONSORT 2010 flow diagram showing the design and progress of the reported study.

respectively, were completed by a movement disorders neurologist, blinded to prior results, during injection visits. The tolerability to BoNT-A was monitored by assessing muscle weakness using a Baseline ${ }^{\circledR}$ hydraulic hand dynamometer (item no. 120240, Fabrication Enterprises, White Plains, New York, USA) to measure maximal grip strength. ${ }^{23}$ Additionally, participants reported any perceived muscle weakness using a Likert-type scale (ranging from $0=$ no, $1=$ mild, $2=$ moderate, $3=$ marked, to $4=$ severe weakness in injected muscles) between study visits. Manual muscle testing (MMT) was used to assess finger flexor/ extensor muscles where scores ranged from $0,1,2-, 2,2+, 3-, 3$, $3+, 4-, 4,4+$, to 5 , with a score of $3+$ or higher representing the ability to hold muscle position against gravity and resist slight pressure. $^{23,24}$

\section{Kinematic Tremor Assessment}

Participants performed a series of scripted tasks while seated with motion sensor devices placed over each arm joint (Figure 2). ${ }^{13,15}$ Goniometers (SG150, Biometrics Ltd., Chester, UK) were placed over the wrist, measuring flexion/extension (F/E) and radial/ulnar (R/U) movement; over the elbow, measuring F/E; and over the shoulder joint, measuring $\mathrm{F} / \mathrm{E}$ and abduction/adduction (Ab/Add) deviations. A torsiometer (Q150, Biometrics) was placed over the forearm to measure pronation/supination $(\mathrm{P} / \mathrm{S})$ deviations about the wrist. A total of four motion sensors were required to capture movement from each joint. A TeleMyo ${ }^{\text {TM }} 2400 \mathrm{~T}$ transmitter with MyoResearch XP Master Edition 1.08.09 (Noraxon ${ }^{\circledR}$, Scottsdale, Arizona, USA) was used to collect motion sensor data.

Four scripted tasks designed to capture tremor composition during two postural tasks ("posture-1" and "posture-2") and two weight-bearing tasks ("load-1" and "load-2") are depicted in Figure 3. ${ }^{13}$ The postural tasks included "posture-1," having participants place their arms out in front of their body with palms facing downward and "posture-2" with their palms facing inward. The weight-bearing tasks, "load-1" and "load-2," involved participants holding an empty and weight-bearing (1-pound weight) cup, respectively. Custom-written software in MatLab ${ }^{\circledR}$ (v. 2011a; MathWorks, Natwick, Massachusetts, USA) was used to process raw sensor angular data. ${ }^{13-16}$ The extracted datasets 


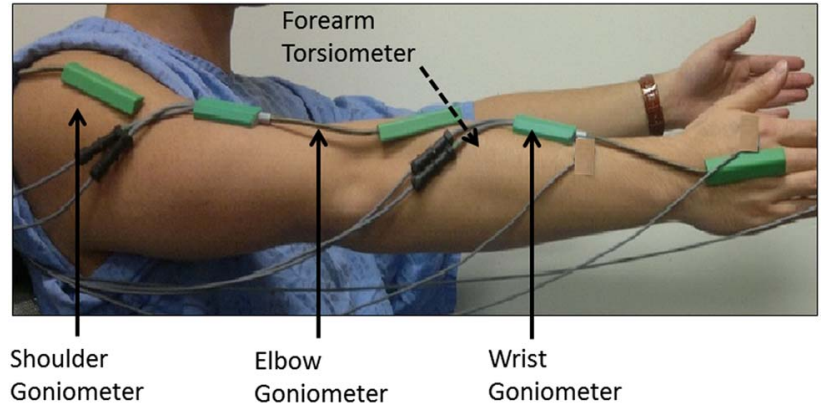

Figure 2: Setup and placement of the multisensor kinematic technology. Denoted by the black solid arrows, a goniometer was placed over each joint. Denoted by the black dotted arrow, a torsiometer was placed along the inside of the forearm.

displayed tremor severity at each arm joint represented as total angular root mean square (RMS) amplitude for each task. Total tremor at the wrist and shoulder joints were further segmented by the amount of tremor, represented as a percentage of the overall tremor, present in each degree of freedom (DOF) that the joint moves in. Such tremor segmentation was denoted "percent contribution of tremor."

\section{Determination of BoNT-A Injection Parameters}

A similar injection determination protocol to that performed by Samotus and Rahimi et al. was utilized. ${ }^{13,15}$ Extracted tremor kinematic data were presented to the movement disorders neurologist prior to injection. Solely using kinematic tremor data, BoNT-A injection parameters were determined for each joint. The total tremor amplitude at each joint was utilized to determine an appropriate BoNT-A dose per joint required to minimize tremor using the injector's best clinical judgment. The total dose allocated to each joint was divided for individual degrees of freedom for each joint using the percent contribution kinematic data, except for the elbow, which moves in one DOF $(\mathrm{F} / \mathrm{E})$ and was not segmented further. Muscles targeted for treatment were selected based on the known anatomical basis of movement. Muscles associated with $\mathrm{F} / \mathrm{E}$ and $\mathrm{R} / \mathrm{U}$ wrist deviations (including the flexor carpi radialis, flexor carpi ulnaris, extensor carpi radialis, and extensor carpi ulnaris) and $\mathrm{P} / \mathrm{S}$ deviations (including the pronator teres, pronator quadratus, and supinator) were targeted when tremor about the wrist was detected. The biceps and triceps were treated when elbow tremor was detected, and the pectoralis major, supraspinatus, deltoid, and teres major were targeted to treat F/E and Abd/Add shoulder tremors. The kinematic tremor results from pre- to

(a)

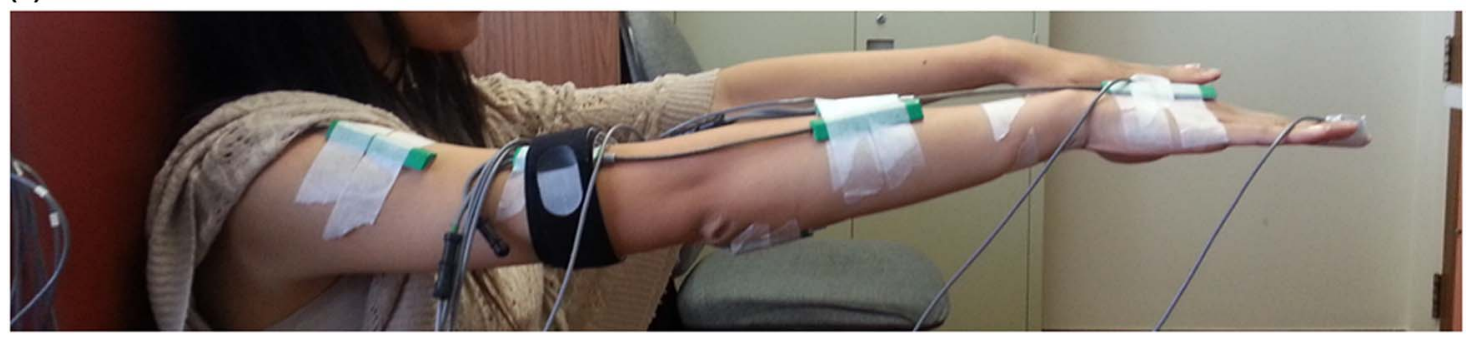

(b)

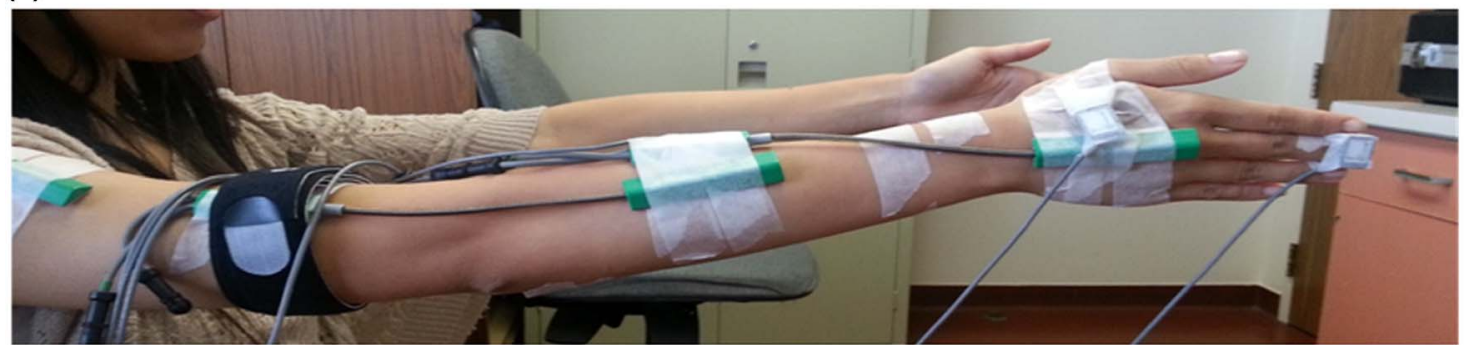

(c)

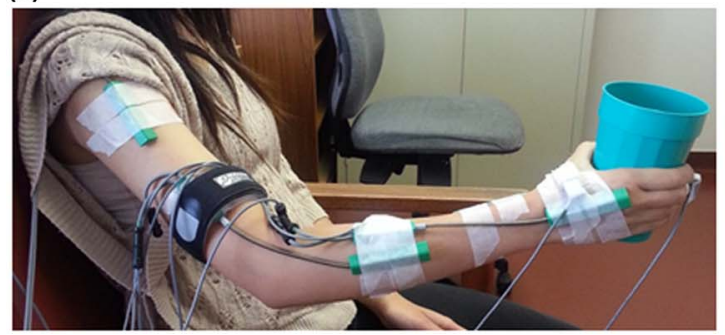

(d)

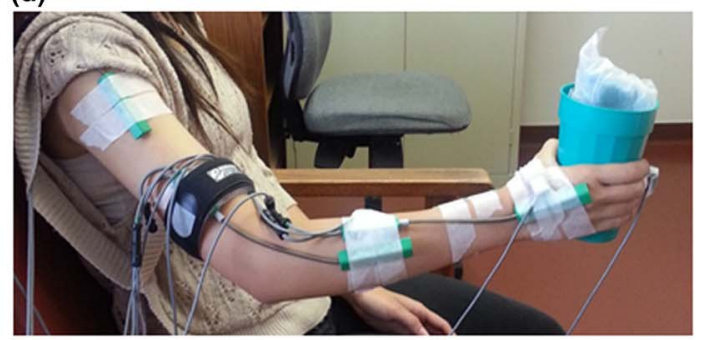

Figure 3: The scripted tasks performed by participants at each timepoint. (a) "Posture-1": both arms outstretched and pronated (palms facing downward) in front of body with shoulders flexed at $90^{\circ}$. (b) "Posture-2": both arms outstretched and palms facing inward. (c) "Load-1": functional task with participant holding an empty cup with the elbow and proximal arm unsupported. (d) "Load-2": functional task with participant holding a weighted cup (1 pound weight) with arm fully unsupported. 
postinjection visits were compared by the injector to determine whether dosages or muscle sites required modification.

\section{Statistical Analysis}

The IBM SPSS statistical software package (v. 21; SPSS Inc., Chicago, Illinois, USA) was employed to analyze the clinical and kinematic data to determine any statistically significant differences across all timepoints. The mean angular RMS tremor amplitude over three trials during each scripted task was calculated at each timepoint and log-transformed as RMS amplitude positively generated skewed distributions. The Shapiro-Wilk test, skewness, and kurtosis z-scores were used to test normality for parametric testing. The datasets did not satisfy the parametric criteria and were subjected to Friedman's test, a nonparametric instrument. Significant mean differences with post-hoc Bonferroni corrections for multiple comparisons were performed between week 0 (pretreatment) and all subsequent posttreatment timepoints, between peak effect timepoints (weeks 6-22-38-54-70-86) and between reinjection timepoints (weeks 0-16-32-48-64-80-96) and within each injection cycle (first treatment: weeks 0-6-16; second treatment: weeks 16-22-32; third treatment: weeks 32-38-48; fourth treatment: weeks 48-54-64; fifth treatment: weeks 64-70-80; sixth treatment: weeks 80-86-96) within the participant population in clinical datasets and kinematic log-transformed datasets.

\section{RESULTS}

\section{Participant Demographics}

The demographics and baseline clinical rating scores of the 10 ET participants naïve to antitremor medications are summarized in Table 2a. At week 86, one participant $(1 / 10 ; 10 \%)$ could not continue due to a fatality resulting from renal failure, unrelated to tremor or the study intervention.

Table $2 \mathrm{~b}$ and Supplemental Table 1 (see Supplementary Materials) outline the total mean dose and number of muscles injected and the dosages per muscle for each injection cycle per participant, respectively. In addition, Supplemental Table 2 (see Supplementary Materials) outlines the mean and range of BoNT-A dosages utilized over all six treatments for all participants. Participants $(n=10)$ were injected in their most bothersome limb as perceived by the participant, and the mean total dose for the first injection was $185.5 \pm 37.1$ units in 9.6 \pm 1.7 muscles (Table $2 b$ ). BoNT-A injections remained unchanged and thus were optimized for the second treatment in four participants $(40 \%)$. By the third treatment, $60 \%$ of participants met the criteria for a satisfactory therapeutic response, and their parameters remained unchanged. Between weeks 32 and 80, 30\% of participants (ID nos. 1, 3, and 8) required no changes to their parameters; $30 \%$ of participants required an increased dose, as ID4 experienced suboptimal benefit, and ID5 and ID7 were experiencing functional benefit and wanted to eliminate tremor for fine motor tasks. A reduction in dose was required for $40 \%$ of participants, based on participant feedback, to minimize lasting weakness in injected muscles, specifically the flexor carpi radialis/ulnaris (FCR/FCU) for wrist flexion weakness and the extensor carpi radialis/ulnaris (ECR/ECU) for wrist extension and grip strength weakness.

FCR and FCU dosages were reduced from a mean of $14.1 \pm 4.4 \mathrm{U}$ for the first treatment to $11.4 \pm 4.9 \mathrm{U}$ for the third treatment. Reductions in ECR and ECU dosages were applied later in the treatment course from a mean of $16.9 \pm 5.2 \mathrm{U}$ for the first treatment to $13.8 \pm 5.1$ $\mathrm{U}$ for the sixth treatment. Dosages applied to the pronators, supinator, biceps, triceps, and shoulder muscles remained relatively constant over the treatment course.

Table 2a: Demographics of ET study participants and baseline UPDRS, QUEST, and FTM parts A-C scores

\begin{tabular}{|c|c|c|c|c|c|c|c|c|c|c|c|}
\hline ID & Gender & Age & $\begin{array}{l}\text { Motor- } \\
\text { dominant } \\
\text { arm }\end{array}$ & $\begin{array}{l}\text { Injected } \\
\text { arm }\end{array}$ & $\begin{array}{l}\text { Arm } \\
\text { circum- } \\
\text { ference } \\
(\mathbf{c m})\end{array}$ & $\begin{array}{c}\text { Weight } \\
\text { (lbs) }\end{array}$ & $\begin{array}{l}\text { Rest tremor } \\
\text { (FTM part } \\
\text { A) } / 4\end{array}$ & $\begin{array}{c}\text { Postural } \\
\text { tremor (FTM } \\
\text { part A) } / 4\end{array}$ & $\begin{array}{c}\begin{array}{c}\text { Action } \\
\text { tremor }\end{array} \\
\text { (FTM part } \\
\text { A) } / 4\end{array}$ & $\begin{array}{c}\text { Functional } \\
\text { disability (FTM } \\
\text { part C) /28 }\end{array}$ & $\begin{array}{c}\text { QUEST } \\
\text { score }\end{array}$ \\
\hline 1 & M & 67 & $\mathrm{R}$ & $\mathrm{R}$ & 38 & 270 & 2 & 4 & 2 & 14 & 39 \\
\hline 2 & F & 64 & $\mathrm{R}$ & $\mathrm{R}$ & 27 & 120 & 2 & 3 & 3 & 21 & 49 \\
\hline 3 & F & 71 & $\mathrm{R}$ & $\mathrm{R}$ & 29 & 140 & 1 & 4 & 0 & 10 & 48 \\
\hline 4 & F & 82 & $\mathrm{R}$ & $\mathrm{L}$ & 26 & 120 & 0 & 0 & 3 & 15 & 22 \\
\hline 5 & F & 65 & $\mathrm{R}$ & $\mathrm{R}$ & 37 & 270 & 1 & 2 & 1 & 12 & 42 \\
\hline 6 & F & 80 & $\mathrm{R}$ & $\mathrm{R}$ & 27 & 130 & 1 & 2 & 1 & 17 & 64 \\
\hline 7 & F & 73 & $\mathrm{R}$ & $\mathrm{R}$ & 36 & 200 & 2 & 2 & 1 & 12 & 22 \\
\hline 8 & M & 84 & $\mathrm{R}$ & $\mathrm{R}$ & 32 & 175 & 0 & 1 & 2 & 20 & 39 \\
\hline 9 & M & 59 & $\mathrm{R}$ & $\mathrm{R}$ & 38 & 227 & 1 & 1 & 1 & 11 & 31 \\
\hline 10 & M & 72 & $\mathrm{~L}$ & $\mathrm{~L}$ & 36 & 237 & 0 & 3 & 2 & 19 & 30 \\
\hline Mean & $4 \mathrm{M}$ & 71.7 & $1 \mathrm{~L}$ & $2 \mathrm{~L}$ & 32.6 & 188.9 & 1 & 2.2 & 1.6 & 15.1 & 38.6 \\
\hline $\pm S D$ & & 8.3 & & & 4.9 & 60.2 & 0.8 & 1.3 & 1.0 & 3.9 & 13.1 \\
\hline Median & & 71.5 & & & 34 & 187.5 & 1 & 2 & 1.5 & 14.5 & 39 \\
\hline Range (low) & & 59 & & & 26 & 120 & 0 & 0 & 0 & 10 & 22 \\
\hline Range (high) & & 84 & & & 38 & 270 & 2 & 4 & 3 & 21 & 64 \\
\hline
\end{tabular}

ET = essential tremor; F = female; FTM = Fahn-Tolosa-Marin tremor rating scale; L = left; $\mathrm{M}=$ male; QUEST = Quality of Life for Essential Tremor Questionnaire; $\mathrm{R}=$ right; $S D=$ standard deviation of the population; UPDRS = Unified Parkinson's Disease Rating Scale. 
Table 2b: Total BoNT-A dose and number of muscles injected for each participant for all treatment cycles

\begin{tabular}{|c|c|c|c|c|c|c|c|c|c|c|c|c|}
\hline \multirow[b]{2}{*}{ ID } & \multicolumn{2}{|c|}{$\begin{array}{c}\text { Week 0 } \\
\text { (1st treatment) }\end{array}$} & \multicolumn{2}{|c|}{$\begin{array}{c}\text { Week } 16 \\
\text { (2nd treatment) }\end{array}$} & \multicolumn{2}{|c|}{$\begin{array}{c}\text { Week } 32 \\
\text { (3rd treatment) }\end{array}$} & \multicolumn{2}{|c|}{$\begin{array}{c}\text { Week } 48 \\
\text { (4th treatment) }\end{array}$} & \multicolumn{2}{|c|}{$\begin{array}{c}\text { Week 64 } \\
\text { (5th treatment) }\end{array}$} & \multicolumn{2}{|c|}{$\begin{array}{c}\text { Week 80 } \\
\text { (6th treatment) }\end{array}$} \\
\hline & $\begin{array}{l}\text { Total } \\
\text { dose }\end{array}$ & $\begin{array}{l}\text { No. of } \\
\text { muscles }\end{array}$ & $\begin{array}{l}\text { Total } \\
\text { dose }\end{array}$ & $\begin{array}{c}\text { No. of } \\
\text { muscles }\end{array}$ & $\begin{array}{l}\text { Total } \\
\text { dose }\end{array}$ & $\begin{array}{c}\text { No. of } \\
\text { muscles }\end{array}$ & $\begin{array}{l}\text { Total } \\
\text { dose }\end{array}$ & $\begin{array}{l}\text { No. of } \\
\text { muscles }\end{array}$ & $\begin{array}{l}\text { Total } \\
\text { dose }\end{array}$ & $\begin{array}{l}\text { No. of } \\
\text { muscles }\end{array}$ & $\begin{array}{l}\text { Total } \\
\text { dose }\end{array}$ & $\begin{array}{l}\text { No. of } \\
\text { muscles }\end{array}$ \\
\hline 1 & 160 & 8 & 290 & 13 & 290 & 13 & 290 & 13 & 290 & 13 & 290 & 13 \\
\hline 2 & 200 & 11 & 100 & 11 & 100 & 11 & 100 & 11 & 80 & 11 & 70 & 9 \\
\hline 3 & 200 & 9 & 150 & 9 & 150 & 9 & 150 & 9 & 150 & 9 & 150 & 9 \\
\hline 4 & 185 & 10 & 185 & 10 & 200 & 13 & 255 & 13 & 255 & 13 & \multicolumn{2}{|c|}{ No injection* } \\
\hline 5 & 200 & 10 & 200 & 10 & 260 & 13 & 280 & 13 & 280 & 13 & 280 & 13 \\
\hline 6 & 200 & 11 & 200 & 11 & 200 & 11 & 200 & 11 & 200 & 11 & 185 & 11 \\
\hline 7 & 180 & 9 & 180 & 9 & 180 & 9 & 145 & 9 & 145 & 9 & 160 & 13 \\
\hline 8 & 235 & 12 & 300 & 12 & 255 & 12 & 275 & 12 & 295 & 14 & 275 & 14 \\
\hline 9 & 95 & 6 & 130 & 6 & 130 & 6 & 130 & 6 & 130 & 6 & 130 & 6 \\
\hline 10 & 200 & 10 & 280 & 11 & 300 & 11 & 300 & 11 & 300 & 11 & 280 & 11 \\
\hline Mean & 185.5 & 9.6 & 201.5 & 10.2 & 206.5 & 10.8 & 203.9 & 10.6 & 212.5 & 11 & 202.2 & 11 \\
\hline $\pm S D$ & 37.1 & 1.7 & 68.7 & 1.9 & 68.4 & 2.3 & 75.3 & 2.2 & 81.5 & 2.4 & 81.1 & 2.6 \\
\hline Median & 200 & 10 & 192.5 & 10.5 & 200 & 11 & 200 & 11 & 227.5 & 11 & 185 & 11 \\
\hline $\begin{array}{l}\text { Range } \\
\text { (low) }\end{array}$ & 95 & 6 & 100 & 6 & 100 & 6 & 100 & 6 & 80 & 6 & 70 & 6 \\
\hline $\begin{array}{l}\text { Range } \\
\text { (high) }\end{array}$ & 235 & 12 & 300 & 13 & 300 & 13 & 300 & 13 & 300 & 13 & 290 & 13 \\
\hline
\end{tabular}

${ }^{*}$ Patient ID4 was not injected at week 80, as patient subjectively found suboptimal benefit with moderate weakness in targeted muscles.

$S D=$ standard deviation of population.

Total dose of BoNT-A is represented by dosage units and is in BoNT-A/incobotulinumtoxinA units.

\section{Kinematic Efficacy}

Objective monitoring of the change in tremor severity pre- and post-BoNT-A treatments was conducted by kinematic tremor assessments for each participant. Illustrated in Figure 4a, mean wrist postural tremor severity captured during task "posture1 " produced a statistically significant difference $\left[\chi^{2}(12)=23.438\right.$, $p=0.024]$ from a mean severity of $0.6 \pm 0.7 \mathrm{RMS}($ median $=0.2)$ at week 0 to $0.3 \pm 0.6 \mathrm{RMS}$ (median $=0.04, p=0.02$ ) at week 6 , though tremor severity was not significantly different at week 16 (median $=0.1, p=0.4$ ). BoNT-A intervention produced a significantly longer-lasting effect on mean wrist postural tremor following the second treatment, with a mean difference of $0.4 \pm 0.2$ RMS at week $32(p=0.02)$ compared to week 0 . Following the second treatment, wrist tremor in "posture-1" was reduced even further from $0.3 \pm 0.5$ at week $16($ median $=0.1)$ to $0.1 \pm 0.2$ at week 64 (median $=0.05, p=0.04$ ). Wrist tremor amplitude during peak effect of BoNT-A was significantly reduced following the third injection at week 38 to weeks 54 and 86 , following the fourth and sixth treatments. Likewise, mean wrist tremor was significantly reduced $\left[\chi^{2}(12)=31.232\right.$, $p=0.002]$ in "posture-2" from $1.0 \pm 0.8($ median $=0.9)$ at week 0 to $0.2 \pm 0.3$ (median $=0.1, p=0.003$ ) at week 6 . A greater reduction in tremor was observed following the second treatment, which was maintained at each reinjection timepoint (at weeks $32,48,64,80$, and 96) to a barely perceivable tremor at week $96(0.1 \pm 0.06$; median $=0.09, p<0.0005)$ (Figure $4 \mathrm{a})$. Wrist tremor severity during "load-1" $\left[\chi^{2}(12)=22.469, p=0.03\right]$ and "load-2" $\left[\chi^{2}(12)=27.503, p=0.007\right]$ functional scripted tasks demonstrated a significant reduction in tremor over the treatment course compared to week 0 , and was even further reduced following the fifth injection between weeks 64 and 80 (Figure 4a). Mean significant reduction in elbow tremor during "posture-2" was reported $\left[\chi^{2}(12)=23.308, p=0.025\right]$ from week $0($ median $=0.2)$ at week $6($ median $=0.07, p=0.037)$ and was maintained at week $80($ median $=0.06, p<0.0005)$. Mean elbow tremor was further significantly reduced between weeks 16 and 80 (46.5\% change) and between weeks 80 and 96 (40.1\% change). Change in tremor severity was not significantly different in the shoulder joint $\left[\chi^{2}(12)=18.264\right.$, $p=0.108$ ] over all scripted tasks over the treatment course (data not shown).

\section{Clinical Efficacy}

Severity of action tremor, rated by mean UPDRS item 21 score, was statistically significantly reduced $\left[\chi^{2}(6)=20.681\right.$, $p=0.002]$ from $2.7 \pm 0.6($ median $=3.0)$ at week 0 to $1.9 \pm 0.9$ at week 48 (median $=1.0, p=0.03$ ) following the fourth treatment (Figure 4b). Mean item 21 score was significantly reduced from $1.9 \pm 0.9$ at week 16 to a mean UPDRS score of $1.0 \pm 0.8$ $(p=0.04)$ at week 96, which demonstrated that tremor was reduced even further over serial treatments. Mean tremor severity at rest (UPDRS item 20) in both limbs and action tremor in the untreated limb did not significantly change over the treatment course compared to week 0 (data not shown). Interestingly, 
(a)

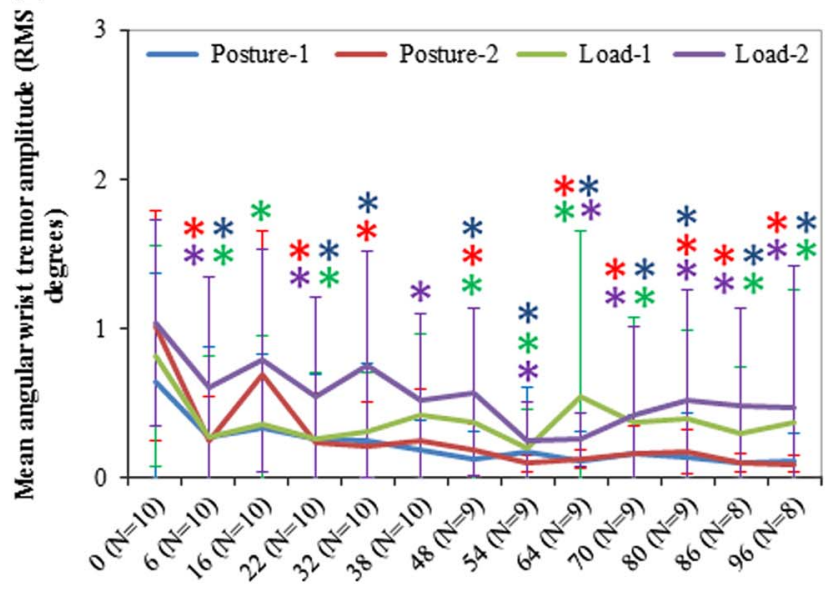

Week (sample size)

(c)

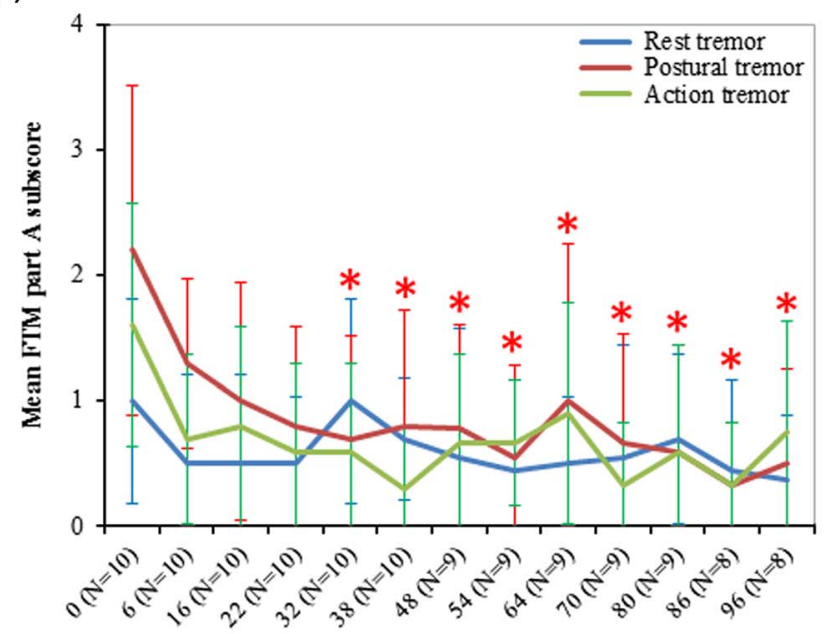

Week (sample size)

(e)

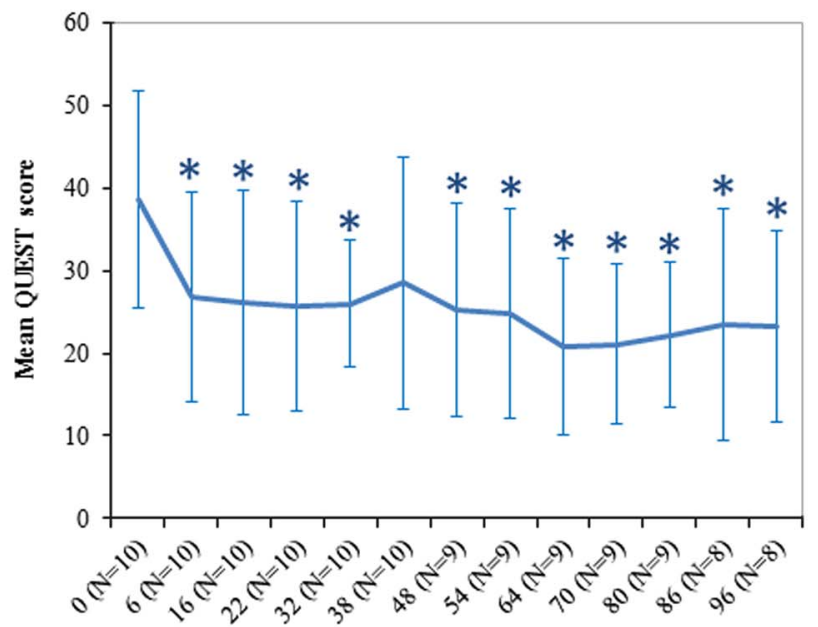

Week (sample size) (b)

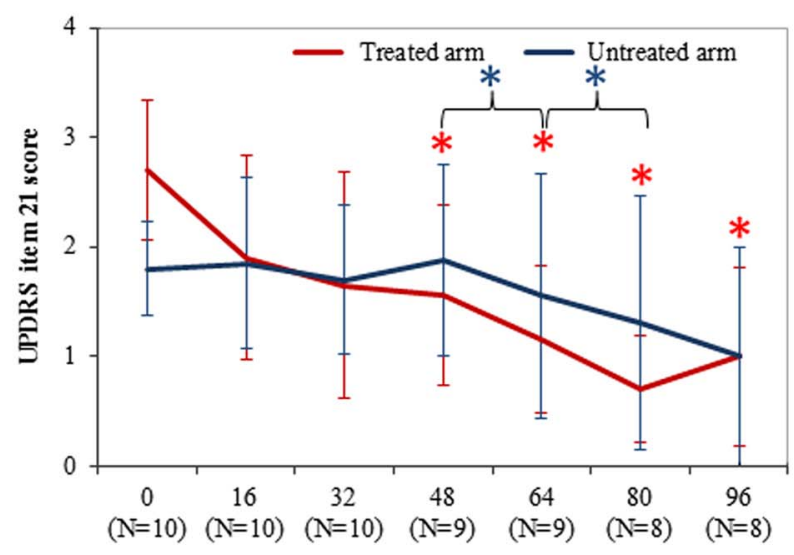

Week (sample size)

(d)

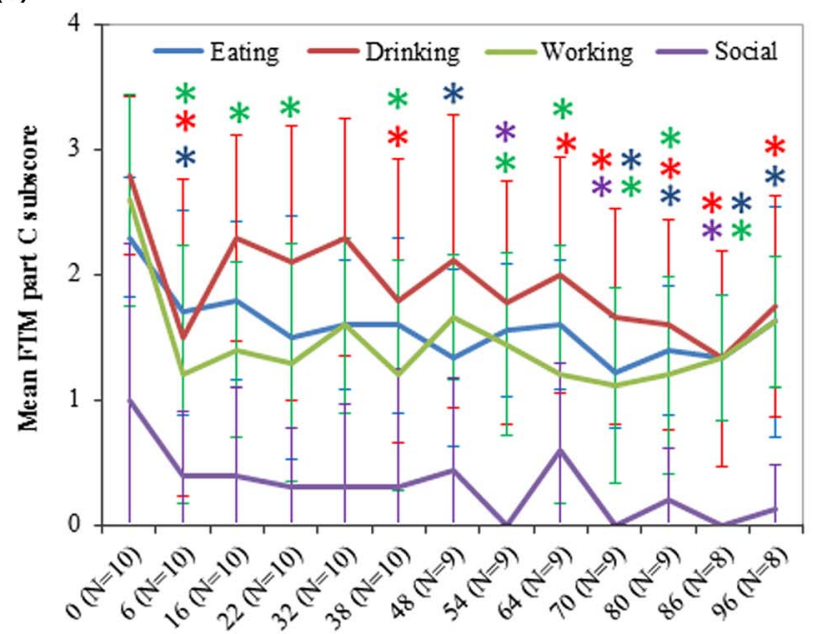

Week (sample size)

(f)

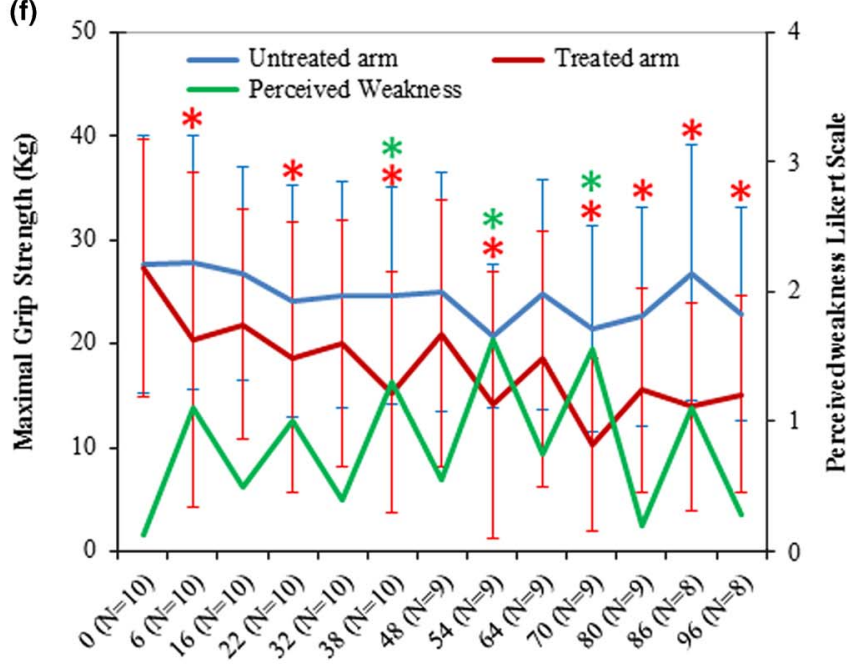

Week (sample size) 
UPDRS item 21 rating of the untreated arm was significantly reduced following the fourth treatment at week $48\left[\chi^{2}(3)=8.561\right.$, $p=0.036]$ from $1.9 \pm 0.9($ median $=2.0)$ to $1.5 \pm 1.1($ median $=$ $1.5, p=0.04)$ at week 64 and to $1.3 \pm 1.2($ median $=1.0, p=0.03)$ at week 80 .

FTM part A assessed tremor severity during posture and action positions are illustrated in Figure 4c. Mean postural tremor was statistically significantly reduced $\left[\chi^{2}(12)=27.591, p=0.006\right]$ from $2.2 \pm 1.3($ median $=2.0)$ at week 0 to $0.7 \pm 0.8$ FTM points at week 32 (median $=0.5, p=0.01)$, and at the time of reinjection and tremor reduction it was maintained at week 96 (median $=0$, $p=0.005$ ). Significant improvement in postural tremor was observed at each peak effect of BoNT-A timepoints between week 6 and weeks $22,38,54,70$ and 86 , resulting in a mean postural tremor severity of $0.3 \pm 0.5 \mathrm{FTM}$ points $($ median $=0, p=0.008)$ at week 86. Mean severity of action tremor was reduced $\left[\chi^{2}(12)=14.730, p=0.2\right]$ from $1.60 \pm 0.9 \quad($ median $=1.5)$ to $0.7 \pm 0.8 \mathrm{FTM}$ points at week $96($ median $=0.5)$, though this was not statistically significant. There was no significant difference in mean rest tremor over the treatment course $\left[\chi^{2}(12)=10.570\right.$, $p=0.556]$, attributed to only $30 \%$ of ET participants $(3 / 10)$ experiencing rest tremor with an FTM score of 2 or higher.

Functional disability caused by tremor was rated by subcategories in FTM part C (Figure 4d). Eating solid foods was significantly improved $\left[\chi^{2}(12)=27.860, p=0.006\right]$ by observing a reduction in mean FTM part $\mathrm{C}$ subscore from $2.3 \pm 0.5$ (median $=$ $2.0)$ at week 0 to $1.7 \pm 0.8$ FTM points at week 6 (median $=2.0$, $p=0.05$ ) following the first treatment, and improvements in eating performance continued to week 96, compared to week 0 , by observing a mean of $1.6 \pm 0.9 \mathrm{FTM}$ points (median $=2.0, p=0.04$ ). Ability to eat significantly improved between the second and fifth injections at weeks 22 and $70(p=0.05)$. Ability to drink liquids was significantly improved $\left[\chi^{2}(12)=27.557, p=0.006\right]$ from $2.8 \pm 0.6$ (median $=3.0$ ) at week 0 to $1.5 \pm 1.2 \mathrm{FTM}$ points at week 6 (median $=1.5, p=0.008$ ). An even greater improvement in drinking ability was achieved following the second treatment at week 22 to week 86 by observing a mean FTM part C subscore of $1.3 \pm 0.9$ (median $=1.0, p=0.03$ ) and following the third treatment at week 32 to week 80, yielding a mean FTM part C drinking score of $1.6 \pm 0.8$ (median $=1.0, p=0.02$ ). Additionally, the ability to perform hobbies and/or work activities was significantly improved $\left[\chi^{2}(12)=23.017, p=0.028\right]$ from $2.6 \pm 0.8($ median $=3.0)$ at week 0 to $1.2 \pm 1.0 \mathrm{FTM}$ points (median $=1, p=0.02$ ) at week 6 , which was maintained over the study course to a mean score of $1.6 \pm 0.5$ FTM points at week 96 (median $=2.0, p=0.05$ ), indicating a change from a marked to mild interference due to ET. FTM part $C$ subcategory for ability to socialize was significantly improved following the fourth treatment at week 48 to week $86\left[\chi^{2}(12)=21.101\right.$, $p=0.049]$. FTM subcategories for hygiene, dressing, speaking, and writing remained statistically unchanged over the treatment course, as these tasks were not functionally impaired by tremor.
Relief of arm tremor severity and functional improvements in activities of daily living was accompanied by a statistically significant improvement $\left[\chi^{2}(12)=33.583, p=0.001\right]$ in QoL, rated by mean QUEST score (Figure 4e). Mean QUEST score was significantly reduced from $38.6 \pm 13.1($ median $=39.0)$ at week 0 to $26.7 \pm 12.7$ (median $=24.0, p=0.032)$ at week 6 . An even greater improvement in QoL was achieved following the third treatment between week 38 and weeks 70 and 86, resulting in a mean QUEST score of 23.4 \pm 14.0 (median 21.0, $p=0.03$ ). QoL scores were further reduced following the fourth treatment at week 48 and were maintained throughout the study to $23.3 \pm 11.6$ $($ median $=23.5, p<0.0005)$ at week 96 .

With improvements in tremor amplitude and arm function, there was a reduction in maximal muscle strength $\left[\chi^{2}(12)=40.135, p<0.0005\right]$ that coincided with peak effect of BoNT-A (Figure 4f). Maximal grip strength was significantly reduced from $27.3 \pm 12.3 \quad($ median $=22.3)$ at week 0 to $20.4 \pm 16.1 \mathrm{~kg}$ force $($ median $=15.8, p=0.004)$ at week 6 , which returned to a mean grip strength of $21.9 \pm 11.1$ (median $=17.0$, $p=0.5$ ) at week 16 . The change in grip strength did not indicate a lasting negative effect on arm function (Figure 4f), as participants experienced a mean Likert score of patient-reported perceived weakness $\left[\chi^{2}(12)=28.244, p=0.005\right]$ of $1.1 \pm 1.1($ median $=1.0$, $p=0.3)$ at week 6 and $0.5 \pm 0.8($ median $=0, p=0.3)$ at week 16 , indicating an absence of to mild weakness in injected muscles 16 weeks following the first treatment. However, following the fourth treatment at week 54, 70\% of participants (7/10) experienced moderate weakness in injected muscles and had mean Likert scores of $1.6 \pm 0.9$, which was reduced to $0.8 \pm 0.8$ at week 64 in $60 \%$ of participants (6/10). This warranted a reduction in dose for the fifth treatment, which ultimately reduced the severity of any lasting weakness from $1.6 \pm 0.9$ at week 70 to $0.2 \pm 0.4$ at week 80 without affecting efficacy or functional improvements. Although there was a $44.6 \%(p<0.0005)$ non-dose-dependent reduction in maximal grip strength at week 96 , only 2 participants complained of mild weakness, resulting in a mean Likert score of $0.3 \pm 0.5$ (median $=0.0, p=0.7$ ).

The MMT assessed loss of strength present in injected muscles. At 6 weeks following a treatment, one or two participants experienced a score of 3 (fair) or lower in the wrist, though weakness in injected muscles was not present at reinjection visits until week 80 for one participant $(10 \%)$ at the sixth treatment visit (Supplemental Figures 1-2; see Supplementary Materials). One participant experienced a reduction in elbow flexion and extension strength at week 86 following the sixth injection, though this was not present at week 96 (data not plotted). MMT testing for finger flexors in the treated arm showed minimal changes in strength over the total 96-week duration. Some 8 participants experienced finger extensor weakness following the fifth injection at week 70, though lasting finger extensor weakness was not present in 6 participants (MMT score $\geq 3$ ), as 2 participants

\footnotetext{
$\overleftarrow{\text { Figure 4: BoNT-A treatments significantly reduced wrist tremor, measured clinically and kinematically, and functional disability with mild muscle }}$ weakness perceived in injected muscles. (a) Mean UPDRS item 21 representing action tremor in the untreated and treated limbs (max: 14). (b) Mean angular RMS tremor amplitude for each scripted task for all participants for each timepoint. Blue asterisks indicate significance in untreated arm compared between the bracketed timepoints. (c) Mean FTM part A subscores for rest, posture, and action tremor for all participants at each timepoint. (d) Mean FTM part C scores for categories that produced significant improvements compared to week 0 scores (max: 14 per task). (e) Mean QUEST score for all participants per timepoint. (f) Mean maximal grip strength measured in untreated and treated limbs and perceived weakness rated by participants using a Likert-type scale. Error bars represent standard deviation of the population. Asterisks indicate a value of $p<0.05$ compared to week 0 , and asterisk colors represent the specific task.
} 
experienced mild weakness (MMT score $\leq 3$ ) at week 80. As finger muscles were not treated with BoNT-A, any weakness in those muscle groups was attributed to spread of toxin.

\section{DISCUSSION}

BoNT-A use has been proven to be an effective localized therapy by reducing tremor severity with a low incidence of muscle weakness, thereby improving arm functionality interfered by tremor. ${ }^{13-15}$ Such improvements have been attributed to the ability of kinematic technology to accurately pinpoint tremulous joints that contribute to ET and to individualize BoNT-A patterns, which past studies had not utilized. ${ }^{10,11,25-27}$ These studies used fixed dosages of BoNT-A into predetermined/randomized muscle groups, thus not an individualized approach, which failed to achieve significant functional improvements, despite at least a 50\% reduction in tremor, due to lasting transient muscle weakness; hence, past studies were limited to one or two injection cycles..$^{10,11,26}$ In addition, clinicians and patients are unenthusiastic about using oral medications as first-line therapy, as patients frequently experience significant adverse events that prompt discontinuation of pharmacotherapy, and approximately a third of patients are secondary nonresponders, as outlined in Table $1 .^{3,7,25-28}$ Thus, effective longterm management of ET is a significant unmet need that stresses the necessity for more targeted treatments available to patients, such as BoNT-A injections. This study is the longest open-label study to demonstrate functional improvement by efficacious and safe management of ET over six serial BoNT-A monotherapy treatments in a cohort of participants.

Kinematics provided an objective output of the dynamics of tremor acting at each arm joint, which in turn was utilized by the injector to choose appropriate dosages to allocate to muscles generating the tremulous movements, previously described by Samotus, Rahimi, and colleagues. ${ }^{13,15}$ This standardized method of assessing tremor personalized initial BoNT-A parameters to each participant's unique tremor signature and permitted long-term objective monitoring for optimization of BoNT-A dosing. Significant improvement in tremor was achieved by focal BoNT-A monotherapy following just one treatment at weeks 6 and 16 (Figure 4), and similar improvements by clinical scales and accelerometry measures of tremor were achieved by level A antitremor medications-primidone and propranolol (Table 1). ${ }^{7,14,15,26-28}$ However, treatment abandonment rates due to dose-dependent undesirable effects by oral medications is as high as $55 \%$ and generally occurs within the first 3 months of treatment. ${ }^{30,32}$ Studies evaluating the long-term efficacy of oral agents have reported that at the end of the first year of treatment patients experienced a 10 to $25 \%$ global improvement in tremor symptoms. ${ }^{30,32}$ Our work has demonstrated that tremor relief by BoNT-A as a monotherapy significantly improves with each serial treatment, producing 74.5 and $77.3 \%$ improvements in postural tremor at week 48 and 96, respectively. Interestingly, action tremor (UPDRS item 21) in the untreated arm was significantly reduced after the fourth treatment, between weeks 48 and 64, and between weeks 48 and 80 , though it was not significantly different between weeks 48 and 96 (Figure 4b). Contralateral BoNT-A effects may be attributed to altered spindle afferent inflow directed to spinal motoneurons, ${ }^{33}$ though further studies are needed to investigate the central modulatory effects of BoNT-A. The ability to personalize and tailor therapy to the dynamic variation of tremor during long-term management of ET is significantly lacking with oral pharmacological agents (outlined in Table 1), as more than $50 \%$ of patients discontinue oral ET therapy due to lack of effect and significant adverse events. ${ }^{26-28}$

Significant functional improvement in activities of daily living tasks (such as eating and drinking), work activities, hobbies, and socializing activities was coupled with significant improvement in QoL scores. Similarly, the effective perceived weakness was minimal and when present was alleviated by dose optimization without loss of efficacy. The change in maximal grip strength did not indicate a lasting negative effect on arm function, as participants perceived any loss in arm strength as mild to moderate 6 weeks following a treatment. A loss in maximal grip strength by more than $20 \%$ is the smallest difference in grip strength that can be perceived by a participant and is mainly attributed to impairment in wrist flexor and extensor muscle groups. ${ }^{24,34}$ Reported from the wrist flexor/ extensor MMT assessments, just 10 to $20 \%$ ( $n=1$ or 2 ) of participants rated a score of 3 (fair) or lower during peak effect of BoNT-A that was diminished at reinjection, demonstrating no negative lasting or functional wrist weakness over the six treatments. Supplemental Figure 2 (see Supplementary Materials) illustrates the number of participants who scored an MMT rating of $\geq 3$ focusing on finger flexors, extensors, abduction, adduction, and wrist flexion and extension muscles plotted with mean perceived weakness Likert scores. This demonstrates a trend with a greater perceivable weakness (mean Likert score of 1.5, indicating mild to moderate perceivable weakness) by participants, peaking at week 70 , and may be attributed to an increase in weakness originating from the finger extensor muscle groups, which were not injected, and thus is a result of spread of toxin. It should be noted that finger extensor weakness (MMT $\leq 3$ ) was not long lasting for 6 of 8 participants at reinjection (week 80 ), and this is also demonstrated by the drop in mean Likert score to 0.2 (slight weakness). These results highlight the benefits of individualization of therapy with kinematics and are credited to the ability of kinematics to personalize injection patterns to each participant's tremor features.

The limitations of our study include a lack of a treatment comparator and nonblinded injections. Blinded studies are challenging with BoNT-A, as muscle weakness is easily perceived by both investigators and participants. ${ }^{27} \mathrm{~A}$ persistent placebo response is unlikely, as this is a longitudinal study where outcomes are objectively determined. Additionally, crossover study designs are complex, as a true baseline in tremor severity is challenging to determine in previously treated participants. The lack of tolerability and efficacy of visually based BoNT-A patterns have been extensively reported in the literature, ${ }^{10-12,25-27}$ and thus the effects of visually based versus kinematically based BoNT-A patterns were not compared. The study's sample size was smaller than in some of the previous literature, ${ }^{11,26}$ as the cohort of participants was specifically those patients who were never treated with any medications. ${ }^{15}$ Participants were assessed at the same time of day to reduce fluctuations in severity at each visit.

Kinematic characterization of upper-limb ET was pivotal for identifying appropriate BoNT-A dosages and muscle groups to inject for each participant. Over the two-year period of serial treatments, participants achieved stable management of their tremor and functional benefit with minimal side effects, which was not achievable with pharmacotherapy alone. Kinematic technology has made personalized BoNT-A injection patterns and optimization of longitudinal management of ET with monotherapy possible. 


\section{ACKNOWLEDGMENTS}

We would like to acknowledge the contribution of the participants and by the postdoctoral engineering and volunteer research staff at the National Parkinson Foundation Centre of Excellence, London Movement Disorder Centre, located within the London Health Sciences Centre, London, Ontario, Canada.

\section{Disclosures}

Olivia Samotus reports grants from MITACS (Merz Pharma), during the conduct of the study.

Mandar Jog reports grants from Merz Pharma, Allergan Inc, Teva Pharmaceuticals, and Abbvie during the conduct of the study. Dr. Jog also reports the following disclosures: grant from Boston Scientific; personal fees received from Ipsen; a grant from Medtronic; personal fees received from MDDT Inc.; and personal fees received from Novartis, In addition, he has a patent (no. PCT/ CA2013/000804) pending to MDDT Inc. and a patent (no. PCT/ CA2014/050893) pending to MDDT Inc.

Niraj Kumar and Philippe Rizek have nothing to disclose.

\section{FUNDING}

The present study was partially funded by a research grant from Merz Pharma Canada and a government/industry matched grant from MITACS (no. IT03924) in partnership with Merz Pharma. Merz Pharma (www.merzcanada.com; grant no. R.14.022) provided funding for this investigator-initiated trial. Dr. Jog's role included study design and supervision, treatment administration, and preparation and decision to publish the manuscript. The funders had no role in study design, data collection and analysis, decision to publish, or preparation of the manuscript. This does not alter our adherence to CJNS policies on sharing data and materials.

\section{Statement of Authorship}

Study concept and design: Mandar Jog.

Study supervision and coordination: Olivia Samotus, Mandar Jog.

Writing/revising content of manuscript: Olivia Samotus, Philippe Rizek, Niraj Kumar, Mandar Jog.

Analysis and interpretation of data: Olivia Samotus, Philippe

Rizek, Niraj Kumar, Mandar Jog.

Statistical analysis: Olivia Samotus.

Obtaining funding: Mandar Jog.

\section{Supplementary Material}

To view the supplementary materials for this article, please visit https://doi.org/10.1017/cjn.2017.260

\section{REFERENCES}

1. Louis ED, Ferreira JJ. How common is the most common adult movement disorder? Update on the worldwide prevalence of essential tremor. Mov Disord. 2010;25(5):534-41.

2. Elble RJ. What is essential tremor? Curr Neurol Neurosci Rep. 2013;13(6):353. https://www.ncbi.nlm.nih.gov/pmc/articles/ PMC3674100/. Accessed August 29, 2017.

3. Deuschl G, Raethjen J, Hellriegel H, Elble R. Treatment of patients with essential tremor. Lancet Neurol. 2011;10(2):148-61.

4. Schneider SA, Deuschl G. The treatment of tremor. Neurotherapeutics. 2014;11(1):128-38.
5. Zesiewicz TA, Elble RJ, Louis ED, et al. Evidence-based guideline update: treatment of essential tremor: report of the Quality Standards Subcommittee of the American Academy of Neurology. Neurology. 2011;77(19):1752-5.

6. Chunling $\mathrm{W}$, Zheng $\mathrm{X}$. Review on clinical update of essential tremor. Neurol Sci. 2016;37(4):495-502.

7. Fasano A, Deuschl G. Therapeutic advances in tremor. Mov Disord. 2015;30(11):1557-65.

8. Picillo M, Fasano A. Recent advances in essential tremor: surgical treatment. Parkinsonism Relat Disord. 2016;22(Suppl 1): S171-5.

9. Elias WJ, Huss D, Voss T, et al. A pilot study of focused ultrasound thalamotomy for essential tremor. N Engl J Med. 2013;369 (7):640-8

10. Jankovic J, Schwartz K, Clemence W, Aswad A, Mordaunt J. A randomized, double-blind, placebo-controlled study to evaluate botulinum toxin type A in essential hand tremor. Mov Disord. 1996;11(3):250-6.

11. Brin MF, Lyons KE, Doucette J, et al. A randomized, double masked, controlled trial of botulinum toxin type A in essential hand tremor. Neurology. 2001;56(11):1523-8.

12. Kim SD, Yiannikas C, Mahant N, Vucic S, Fung VS. Treatment of proximal upper limb tremor with botulinum toxin therapy. Mov Disord. 2014;29(6):835-8.

13. Samotus O, Rahimi F, Lee J, Jog M. Functional ability improved in essential tremor by incobotulinumtoxinA injections using kinematically determined biomechanical patterns: a new future. PLoS One. 2016;11(4):e0153739. https://www.ncbi.nlm.nih.gov/pmc/ articles/PMC4839603/. Accessed August 29, 2017.

14. Rahimi F, Bee C, Debicki D, Roberts AC, Bapat P. Effectiveness of BoNT A in Parkinson's disease upper limb tremor management. Can J Neurol Sci. 2013;40(5):663-9.

15. Rahimi F, Samotus O, Lee J, Jog M. Effective management of upper limb parkinsonian tremor by incobotulinumtoxinA injections using sensor-based biomechanical patterns. Tremor Other Hyperkinet Mov. 2015;5:348. https://www.ncbi.nlm.nih.gov/pmc/ articles/PMC4636031/. Accessed August 29, 2017.

16. Rahimi F, Debicki D, Roberts-South A, Bee C, Bapat P, Jog M. Dynamic decomposition of motion in essential and parkinsonian tremor. Can J Neurol Sci. 2015;42(2):116-24.

17. Supuk T, Bajd T, Kurillo G. Assessment of reach-to-grasp trajectories toward stationary objects. Clin Biomech (Bristol. Avon). 2011;26(8):811-8.

18. Casellato C, Zorzi G, Pedrocchi A, Ferrigno G, Nardocci N. Reaching and writing movements: sensitive and reliable tools to measure genetic dystonia in children. J Child Neurol. 2011;26(7): 822-829.

19. Product Monograph: IncobotulinumtoxinA. Xeomin Product Monograph. Merz Pharmaceuticals; 2013.

20. Tröster AI, Pahwa R, Fields JA, Tanner CM, Lyons KE. Quality of life in the Essential Tremor Questionnaire (QUEST): development and initial validation. Parkinsonism Relat Disord. 2005;11 (6):367-73.

21. Hess CW, Pullman SL. Tremor: clinical phenomenology and assessment techniques. Tremor Other Hyperkinet Mov. 2012:2. https:// www.ncbi.nlm.nih.gov/pmc/articles/PMC3517187/. Accessed August 29, 2017.

22. Goetz CG, Tilley BC, Shaftman SR, et al. Movement Disorder Society-sponsored revision of the Unified Parkinson's Disease Rating Scale (MDS-UPDRS): scale presentation and clinimetric testing results. Mov Disord. 2008;23(15):2129-70.

23. Schreuders TA, Selles RW, Roebroeck ME, Stam HJ. Strength measurements of the intrinsic hand muscles: a review of the development and evaluation of the Rotterdam intrinsic hand myometer. J Hand Ther. 2006;19(4):393-402.

24. MacDermid JC. Measurement of health outcomes following tendon and nerve repair. J Hand Ther. 2005;18(2):297-312.

25. Pacchetti C, Mancini F, Bulgheroni $M$, et al. Botulinum toxin treatment for functional disability induced by essential tremor. Neurol Sci. 2000;21(6):349-53.

26. Trosch RM, Pullman SL. Botulinum toxin A injections for the treatment of hand tremors. Mov Disord. 1994;9(6):601-9. 
27. Pullman SL, Greene P, Fahn S, Pedersen S.. Approach to the treatment of limb disorders with botulinum toxin A: experience with 187 patients. Arch Neurol. 1996;53:617-24.

28. Sadeghi R, Ondo WG. Pharmacological management of essential tremor. Drugs. 2010;70(17):2215-28.

29. Zesiewicz TA, Elble RJ, Louis ED, et al. Practice parameter: therapies for essential tremor: report of the Quality Standards Subcommittee of the American Academy of Neurology. Neurology. 2005;64(12):2008-20.

30. Zesiewicz TA, Shaw JD, Allison KG, Staffetti JS, Okun MS, Sullivan KL. Update on treatment of essential tremor. Curr Treat Options Neurol. 2013;15(4):410-23.

31. Lyons KE, Pahwa R. Pharmacotherapy of essential tremor: an overview of existing and upcoming agents. CNS Drugs. 2008;22(12):1037-45.
32. Serrano-Dueñas M. Use of primidone in low doses $(250 \mathrm{mg} / \mathrm{day})$ versus high doses $(750 \mathrm{mg} / \mathrm{day})$ in the management of essential tremor: double-blind comparative study with one-year follow-up. Parkinsonism Relat Disord. 2003;10(1):29-33.

33. Currà A, Trompetto C, Abbruzzese G, Berardelli A. Central effects of botulinum toxin type A: evidence and supposition. Mov Disord. 2004;19(Suppl 8):60-4.

34. Kim JK, Park MG, Shin SJ. What is the minimum clinically important difference in grip strength? Clin Orthop Relat Res. 2014;472(8):2536-41.

35. Zesiewicz TA, Chari A, Jahan I, Miller AM, Sullivan KL. Overview of essential tremor. Neuropsychiatr Dis Treat. 2010;6: 401-8; https://www.ncbi.nlm.nih.gov/pmc/articles/PMC2938289/. Accessed August 29, 2017. 